\title{
pro.posições
}

\section{Percepção e conhecimento de futuros professores sobre seus processos de aprendizagem}

\section{Perception and knowledge of future teachers of their learning processes}

\section{Percepción y conocimiento de futuros profesores sobre sus procesos de aprendizaje}

Neide de Brito Cunha*

Evely Boruchovitch ${ }^{* *} 1$

*Universidade do Vale do Sapucaí, Pós-Graduação Stricto Sensu, Pouso Alegre, MG, Brasil. neidedebritocunha@gmail.com

**Universidade Estadual de Campinas - Unicamp, Faculdade de Educação, Campinas, SP, Brasil. evely@unicamp.br

\begin{abstract}
Resumo
Este trabalho objetivou levantar os conhecimentos que os futuros professores tinham a respeito de suas estratégias de aprendizagem. Participaram 62 estudantes, de cursos de Pedagogia e Matemática, de uma universidade pública e outra particular de dois estados brasileiros. Os dados foram coletados por meio do Protocolo de Ativação da Metacognição e da Autorreflexão sobre a Aprendizagem do Futuro Professor e examinados pela análise de conteúdo. Os resultados mostram não só que os estudantes que aspiram ser professores refletem sobre sua aprendizagem e se preocupam em processar a informação de maneira mais profunda, mas também que o autoconhecimento se constitui em instrumento importante para ajudar alunos a aprender a aprender. Do total de participantes, $70 \%$ declararam utilizar estratégias cognitivas, enquanto somente $30 \%$ mencionaram as metacognitivas. Aventa-se que haja falta de instrução adequada quanto ao uso de estratégias de aprendizagem no contexto educacional de formação do professor.

Palavras-chave: metacognição, formação de professores, autorregulação
\end{abstract}

${ }^{1}$ A autora agradece o apoio financeiro do CNPq. 


\section{pro.posıções}

\section{Abstract}

This study was targeted at assessing the knowledge of future teachers about their own learning strategies. The sample was composed of 62 students from pedagogy and mathematics courses, of public and private universities of two Brazilian states. Data was collected using the Future Teacher Self-reflection of Learning and Metacognition Activation Protocol and examined by content analysis. Results showed not only that the students reflect on their learning and are concerned with deep processing of information, but also that self-reflection can be an important tool to help students learn how to learn. Of the total sample, 70\% reported using cognitive strategies while only $30 \%$ mentioned the metacognitive ones. It can be inferred that there is lack of adequate instruction regarding the use of learning strategies in the context of teacher education. Keywords: metacognition, teacher education, self-regulation

\section{Resumen}

Este trabajo objetivó plantear los conocimientos que los futuros profesores tenian respecto a sus estrategias de aprendizaje. Participaron 62 estudiantes de cursos de pedagogía y matemáticas, de una universidad pública y otra particular de dos estados brasileños. Se recogieron los datos a través del Protocolo de Ativação da Metacognição e da Autorreflexão sobre a Aprendizagem do Futuro Professor, que fueron examinados por el análisis de contenido. Los resultados mostraron que los estudiantes que aspiran ser profesores reflexionan sobre su aprendizaje y se preocupan en procesar la información con mayor profundidad y que creen que el autoconocimiento es una berramienta importante para ayudar a los alumnos a aprender cómo aprender. De los de participantes, $70 \%$ reportaron utilizar estrategias cognitivas y solamente el 30\% mencionaron las metacognitivas. Se sugiere que baya falta de instrucción adecuada cuanto al uso de estrategias de aprendizaje en el contexto educacional de formación del profesorado.

Palabras clave: metacognición, formación del profesorado, autorregulación 


\section{pro.posições}

A capacidade de o indivíduo pensar sobre os seus próprios pensamentos, levando em conta alcançar níveis mais altos de autoconsciência, é denominada metacognição. Ela é um conceito muito estudado dentro da psicologia moderna, principalmente na psicopedagogia (Noriega, 2008; Torrano \& González-Torres, 2004; Ugartetxea, 2001). Pesquisas relativas à metacognição revelam que ela é imprescindível para que as pessoas utilizem estratégias de aprendizagem, essenciais para a melhoria do desempenho de alunos em diversos campos do saber (Dunlosky, 1998; Weinstein, Acee, \& Jung, 2011).

Aprender a aprender implica ser capaz de procurar a informação quando dela se necessita, aprender novas maneiras de pensar e de estudar, dirigir as atividades da própria aprendizagem, desenvolver a autonomia, ser capaz de aplicar e transferir as estratégias para situações, tarefas e problemas semelhantes. Envolve, também, tornar-se progressivamente independente dos professores (Bembenutty, 2011; Pinto, 1998).

Nesse sentido, o professor também deveria ser estratégico tanto para aprender quanto para ensinar. Monereo e Clariana (1993) acreditam que o docente deve ser um profissional que apresenta competências reguladoras que tornam possíveis o planejamento, o monitoramento e a avaliação dos seus processos cognitivos, tanto quando aprende como quando ensina. Veiga Simão (2004) considera que o professor, aprendiz de estratégias, que deseja ensiná-las ao aluno, deverá reconhecer que, no preparo de suas aulas, precisa perceber como aprende ou aprendeu, e quando e com que finalidade fará uso do conteúdo aprendido. Sem dúvida, estudiosos defendem que oportunidades que favoreçam o desenvolvimento de uma atitude reflexiva, ativa e construtiva devem fazer parte da sua formação (Middleton, Abrams, \& Seaman, 2011; Randi, 2004).

As estratégias de aprendizagem são definidas por Nisbett e Shucksmith (1986) e Dansereau (1978) como sequências integradas de procedimentos ou atividades que se escolhem com a intenção de facilitar a aquisição, o armazenamento e/ou a utilização da informação. Para Silva e Sá (2007), elas são procedimentos adotados para a realização de uma determinada tarefa.

A literatura mostra várias possibilidades de categorização das estratégias de aprendizagem que os alunos utilizam em suas tarefas escolares. Somuncuoglu e Yildirim (1999) e Boruchovitch e Santos (2006) consideram que as principais definições e classificações podem ser agrupadas em duas esferas principais: estratégias cognitivas e metacognitivas. As 


\section{pro.posıções}

estratégias cognitivas são, por sua vez, subdivididas em estratégias de ensaio, elaboração e organização e ajudam os alunos a codificar, a organizar e a reter a nova informação. As estratégias metacognitivas envolvem ações como planejar, monitorar e regular, ou seja, o controle e a execução de processos de aprendizagem (Dembo, 1994; Somuncuoglu \& Yildirim, 1999).

As estratégias de aprendizagem, especificamente do professor em exercício ou do futuro professor na condição de estudante, foram pesquisadas, no âmbito internacional, nos últimos dez anos, por Quezada (2005), que utilizou o Inventário de Estratégias de Estudo e Aprendizagem e encontrou pontuação baixa nas categorias de motivação, estratégias para a preparação e apresentação de exames e adequação à ansiedade. Também Gilar, Martinez Ruiz e Costa (2006) analisaram os diários dos alunos e estudaram as estratégias de aprendizagem utilizadas por um grupo de futuros professores em uma situação de aprendizagem real. Os autores sugeriram que as estratégias de aprendizagem precisam ser desenvolvidas diretamente pelo professor ou incluídas nos programas de formação de professores.

Os benefícios provenientes do uso dessas estratégias e da criação de espaços nos cursos de formação de professores para sua instrução foram apontados em outros trabalhos. McVarish e Salvatore (2005) desenvolveram um estudo qualitativo em duas classes de uma universidade particular. Os docentes participantes mantinham um jornal reflexivo, em que registravam o que aprendiam, observavam, experienciavam e pensavam em relação à própria aprendizagem matemática. Os autores argumentaram que, como professores universitários, suas metas não deveriam ser limitadas a ajudar os alunos a aprender o que se esperava que entendessem. Mais que isso, deveriam auxiliá-los a serem aprendizes reflexivos. Concluíram que é importante que futuros professores e professores na ativa aprendam como ensinar, sendo avaliadores críticos da própria aprendizagem. De modo semelhante, Knight, Tait e Yorke (2006) realizaram uma pesquisa na Universidade do Reino Unido, com 2.536 professores, em que analisaram a aprendizagem profissional no Ensino Superior, destacando a importância da reflexão como o motor da aprendizagem profissional.

Numa perspectiva mais voltada para intervenção, Perry, Phillips e Hutchinson (2006) investigaram a possibilidade de estudantes de licenciatura desenvolverem práticas associadas com a aprendizagem autorregulada quando recebem instrução explícita e apoio intensivo para agir desta maneira em seu curso de formação para professores. Os resultados evidenciaram 


\section{pro.posıções}

que os futuros docentes conseguiam desenvolver tarefas e se envolver em práticas promotoras da aprendizagem autorregulada. Os autores chegaram à conclusão de que os professores estariam mais dispostos a partilhar o controle do ensino e da aprendizagem com os alunos quando se sentissem seguros da eficiência deste recurso.

Numa mesma direção, Romanowski e Rosenau (2006) analisaram as contribuições dos processos metacognitivos para a melhoria da capacidade de aprendizagem de 114 alunos do curso de Pedagogia. Foram utilizados 5 instrumentos, sendo 3 questionários fechados e 2 abertos. Ao examinar criticamente os dados, as autoras concluíram que os estudantes tomaram consciência das suas atitudes como alunos por meio do uso desses instrumentos, o que produziu em muitos a vontade de aumentar sua capacidade de aprender.

Cázares e Rico (2009) identificaram e analisaram em sua pesquisa as estratégias metacognitivas utilizadas por estudantes de licenciatura. Os resultados confirmaram os achados de outras pesquisas de que alunos dos anos iniciais reportam menor uso de estratégias de aprendizagem e/ou utilizam as superficiais, como as de ensaio, ao passo que os mais avançados na escolaridade tendem a mencionar maior emprego das metacognitivas. Donche e Van Petegem (2009) também encontraram maior capacidade de autorregulação com o avanço no ensino em universitários de cursos de formação de professores, bem como a relação positiva entre o uso de estratégias de aprendizagem e o desempenho acadêmico.

Já, no Brasil, pesquisas especificamente com o professor em exercício ou futuro professor na condição de estudante foram realizadas por Frison e Moraes (2010), que estudaram os processos de autorregulação da aprendizagem e a monitoria no Ensino Superior. Foi realizada uma investigação focada no quanto as práticas de monitoria possibilitariam a vivência de processos de autorregulação das aprendizagens discentes, auxiliando os alunos a se apropriarem da regulação do seu próprio processo de aprender, numa perspectiva que transcendesse aos aspectos puramente conceituais. As autoras encontraram que a monitoria contribuiu para a aprendizagem, ao mesmo tempo em que preparou e formou professoresprofissionais qualificados para assumirem o ensino.

Também Santos e Boruchovitch (2011) buscaram conhecer o professor enquanto estudante, seu conhecimento e uso de estratégias de aprendizagem, coletando dados por meio de entrevista com questões relativas às estratégias de aprendizagem e de uma Escala de Avaliação de Estratégias de Aprendizagem. Os resultados revelaram que muitas professoras 


\section{pro.posições}

em exercício confundiram o conceito de estratégias de aprendizagem com estratégias de ensino. A concepção de aprender a aprender também se apresentou equivocada. Os dados obtidos por meio da escala indicaram que o relato de uso de estratégias cognitivas e metacognitivas foi percentualmente próximo.

Bortoletto e Boruchovitch (2013) investigaram as relações entre as estratégias de aprendizagem e de regulação emocional de alunos de cursos de Pedagogia. Os dados foram coletados por meio de uma escala de estratégias de aprendizagem e outra de regulação emocional. Os resultados evidenciaram uma correlação positiva, moderada e significativa entre as estratégias de aprendizagem e as de regulação emocional dos participantes.

Numa perspectiva mais orientada à intervenção nos processos autorregulatórios, Boruchovitch e Ganda (2013) ministraram uma disciplina de Psicologia Educacional para graduandos em Pedagogia, cujo objetivo foi o de aumentar a consciência da aprendizagem pessoal dos futuros professores, por meio de exercícios autorreflexivos e de diários de aprendizagem. Os resultados mostraram ganhos nas habilidades de autorregulação, uma maior consciência dos estados afetivos e motivacionais e uma melhora da técnica de estudo, entre os participantes, além da aprendizagem do conteúdo.

Marini e Boruchovitch (2014) investigaram universitários que desejavam ser professores, por meio de uma escala tipo Likert e dois protocolos autorreflexivos orientados à avaliação do conhecimento, da utilização, da consciência e da importância que concedem ao uso de estratégias de aprendizagem. Os dados da amostra apontaram para um emprego predominante de estratégias superficiais, certa consciência dos próprios processos cognitivos e metacognitivos, bem como uma tendência a confundir as estratégias de aprendizagem com as de ensino.

Assim, considerando a relevância da temática, a escassez de pesquisas nacionais sobre a reflexão acerca da própria aprendizagem e o emprego de estratégias de aprendizagem por parte de estudantes que aspiram ser professores, o presente estudo teve os seguintes objetivos: levantar informações acerca de como futuros professores pensam e autoavaliam o seu aprender e caracterizar as suas estratégias de aprendizagem, bem como o seu conhecimento a respeito delas. 


\section{pro.posıções}

\section{Método}

\section{Participantes}

A amostra foi composta por 62 alunos do curso de Pedagogia de uma universidade pública $(n=58)$ e $6,45 \%(n=4)$ do $8^{\circ}$ semestre do curso de Matemática de uma universidade particular. Dos estudantes que se dispuseram a participar da pesquisa, 4,84\% $(n=3)$ eram homens e 95,16\% ( $n=59)$, mulheres. Do total, 35,48\% ( $n=22)$ eram do $2^{\circ}$ semestre, $29,03 \%$ $(\mathrm{n}=18)$ do $4^{\circ}, 29,03 \%(\mathrm{n}=18)$ do $6^{\circ}$.

\section{Instrumento}

Foi utilizado o Protocolo de Ativação da Metacognição e da Autorreflexão sobre a Aprendizagem do Futuro Professor (Boruchovitch, 2009) cuja finalidade é conhecer as características dos alunos e fazê-los pensar sobre sua própria aprendizagem, numa dupla vertente: como estudantes e como futuros profissionais. A pesquisa averigua, também, se os estudantes conhecem estratégias de aprendizagem e sua opinião sobre elas.

O protocolo é composto de seis questões abertas e fechadas, a saber: 1 - Você costuma pensar sobre sua aprendizagem ou sobre como você aprende? Justifique. 2 - Você acha que pensar sobre seu próprio processo de aprendizagem pode ser útil para você como aluno? Justifique. 3 - Você acha que pensar sobre seu próprio processo de aprendizagem pode ser útil para você como futuro professor? Justifique. 4 - Quando você tem uma tarefa ou deseja estudar e aprender melhor algum conteúdo, como você faz? Descreva em detalhes. 5 Você já ouviu falar em estratégias de aprendizagem? Sim ou não. 6 - Em sua opinião, o que são estratégias de aprendizagem?

\section{Procedimentos de coleta de dados}

Primeiramente, a pesquisa foi submetida e aprovada pelo Comitê de Ética em Pesquisa da Universidade São Francisco (Protocolo CAAE: 0151.0.142.000-09). Em seguida, foram contatados os diretores das instituições de Ensino Superior que aprovaram a coleta de dados, 


\section{pro.posições}

para a apresentação dos objetivos da pesquisa e dos cuidados éticos tomados com base na Resolução no 196/96, do Ministério da Saúde.

O instrumento foi aplicado coletivamente, nas salas de aula, em horário de maior conveniência dos professores. Os participantes foram assegurados de que a pesquisa não influenciaria na nota, não afetaria o seu desempenho acadêmico na universidade, além de ser de caráter estritamente confidencial. Foram também orientados a, primeiramente, preencher o Termo de Consentimento Livre e Esclarecido e, em seguida, responder às questões que constavam no próprio protocolo. O tempo gasto para o preenchimento do instrumento foi, em média, de 30 minutos. Os estudantes que não quiseram participar da pesquisa puderam sair das salas de aula no momento da aplicação do instrumento.

\section{Procedimentos de análise dos dados}

As respostas dos participantes às questões foram agrupadas de acordo com seu conteúdo, analisadas qualitativamente, mediante a categorização de respostas (Bardin, 2009), e descritas em porcentagem, por meio dos procedimentos da estatística descritiva. Cada categoria foi definida operacionalmente, e regras para a classificação de uma resposta numa dada categoria foram criadas, com base na literatura da área (Boruchovitch \& Santos, 2006; Brophy \& Good, 1986; Dembo, 1994; Somuncuoglu \& Yildirim, 1999). A consistência do processo de categorização foi avaliada por um juiz, doutor em Avaliação Psicológica Educacional. O percentual de concordância entre o juiz e as pesquisadoras variou de 86 a 92\%. Definições e exemplos das categorias podem ser vistas no Apêndice.

\section{Resultados}

A primeira pergunta versava sobre o fato de o estudante costumar pensar sobre sua aprendizagem ou sobre a forma como aprende, bem como suas justificativas. Os dados revelaram que 98,38\% ( $n=61)$ dos estudantes responderam “sim”, e 1,62\% (n=1), "não". As respostas foram agrupadas em cinco categorias de acordo com seu foco, como recomendado por Bardin (2009). As respostas positivas obtidas e sua frequência podem ser observadas na Tabela 1. 


\section{pro.posições}

Tabela 1 - Questão 1: Você costuma pensar sobre sua aprendizagem ou como você aprende?

\begin{tabular}{lrr}
\hline \multicolumn{1}{c}{ Categorias de respostas } & N & \multicolumn{1}{c}{$\%$} \\
\hline Reflexão sobre a melhor maneira de aprender & 27 & 44,26 \\
Não ofereceram justificativa & 14 & 21,31 \\
Qualidade da atuação profissional & 11 & 18,03 \\
Utilidade da aprendizagem & 7 & 11,48 \\
Dependência da explicação do professor & 3 & 4,92 \\
Total & 62 & 100 \\
\hline
\end{tabular}

Foi interessante notar que 44,26\% (n=27) dos estudantes refletem sobre sua aprendizagem. O número de alunos que não ofereceram justificativa foi elevado, 21,31\% $(n=13)$, ficando em segundo lugar na ordem de frequência das categorias de respostas. Os estudantes se preocupam em ser bons profissionais $(18,03 \%$ [ $n=11])$ e refletem se o que aprendem terá utilidade $(11,48 \%[\mathrm{n}=7])$. No entanto, parecem ter dificuldade em se perceber como estudantes, pois focam mais na sua atuação profissional.

A segunda pergunta examinava se o participante considerava útil pensar sobre o próprio processo de aprendizagem e solicitava sua justificativa. Todos responderam que sim. De acordo com o foco das respostas, foram criadas quatro categorias, que podem ser vistas no Apêndice. As respostas e as suas respectivas porcentagens se encontram na Tabela 2.

Tabela 2 - Questão 2: Você acha que pensar sobre seu próprio processo de aprendizagem pode ser útil para você como aluno?

\begin{tabular}{lcc}
\hline \multicolumn{1}{c}{ Categorias de respostas } & N & \% \\
\hline Significação da aprendizagem & 34 & 54,82 \\
Identificação da melhor forma de aprender & 11 & 17,74 \\
Importância para a atuação profissional & 10 & 16,12 \\
Não ofereceram justificativa & 7 & 11,29 \\
Total & 62 & 100 \\
\hline
\end{tabular}




\section{pro.posıções}

Pode ser observado que a categoria mais frequente $(54,82 \%$ [n=34]) foi: "Significação da aprendizagem”, seguida da "Identificação da melhor forma de aprender" $(17,74 \%$ [n=11]). Nessa direção, percebe-se que 16,12\% $(n=10)$ dos estudantes fazem um elo entre sua própria aprendizagem e seu futuro exercício profissional.

Em seguida, a questão 3 abordava a utilidade de pensar sobre o próprio processo de aprendizagem, com foco na atuação profissional e suas justificativas. Encontrou-se que $98,38 \%(n=61)$ responderam que sim e 1,62\% (n=1), que não. As respostas positivas a essa questão foram agrupadas nas três categorias que podem ser visualizadas no Apêndice.

Tabela 3 - Questão 3: Você acha que pensar sobre seu próprio processo de aprendizagem pode ser útil para você como futuro professor?

\begin{tabular}{lcc}
\hline \multicolumn{1}{c}{ Categorias de respostas } & N & \% \\
\hline Qualidade da atuação profissional & 37 & 59,67 \\
Avaliação dos alunos & 14 & 22,58 \\
Não ofereceram justificativa & 11 & 17,74 \\
Total & 62 & 100 \\
\hline
\end{tabular}

Como mostra a Tabela 3, na categoria "Qualidade da atuação profissional", para a qual houve o maior número de respostas, 59,67\% ( $\mathrm{n}=37)$, há realmente relação entre o autoconhecimento e sua importância para ter confiança e tranquilidade para exercer a profissão. Percebe-se, pois, uma relação entre essa resposta e a que apareceu em segundo lugar, com 22,58\% ( $\mathrm{n}=14)$ : “Avaliação dos alunos". Vale ainda destacar que o número de alunos que não ofereceram justificativas para suas respostas foi bem elevado $17,74 \%$ ( $n=11)$, sobretudo quando se considera que a amostra foi composta de estudantes que aspiram ser futuros professores.

A questão 4 perguntava o que os estudantes faziam quando tinham uma tarefa ou desejavam estudar e aprender melhor algum conteúdo e pedia que descrevessem em detalhes esses procedimentos. As repostas foram agrupadas em categorias, de acordo com a Taxionomia das estratégias de aprendizagem desenvolvida por Mckeachie et al. (1990, citados por Dembo, 1994), amplamente utilizada na literatura da área, descrita por Boruchovitch (1999). A Tabela 4 apresenta as respostas dos participantes e sua frequência. 


\section{pro.posıções}

Tabela 4 - Questão 4: Quando você tem uma tarefa ou deseja estudar melhor algum conteúdo, como você faz?

\begin{tabular}{llcc}
\hline & \multicolumn{1}{c}{ Respostas } & Total & \% \\
\hline \multirow{3}{*}{ Ensaio } & \multicolumn{1}{c}{ Estratégias cognitivas } & & \\
& Leitura dos textos & 31 & 25 \\
& Memorização & 1 & 1,24 \\
Elaboração & Destaque das partes importantes & 1 & 1,24 \\
& Pesquisa em livros, revistas científicas, dicionário, internet & 32 & 25,80 \\
& Autoexplicação & 8 & 6,25 \\
& Escrita do que entendeu & 8 & 6,25 \\
& Elaboração de resumo & 4 & 3,02 \\
Total & Elaboração de exercícios & 1 & 1,24 \\
& & 86 & 70,00 \\
Planejamento & Estudar de madrugada & & \\
Monitoramento & Prestar mais atenção nas aulas & & \\
Regulação & Procurar o professor ou colegas & 1 & 1,24 \\
& Procurar um lugar silencioso para estudar & 1 & 1,24 \\
& Rever as anotações feitas em sala de aula & 24 & 19,06 \\
Total & Ficar perdido & 7 & 4,04 \\
& & 4 & 3,20 \\
& & 1 & 1,24 \\
& & 38 & 30,00 \\
\hline
\end{tabular}

Para essa pergunta, os estudantes responderam com mais de uma descrição de estratégias de aprendizagem, totalizando 124 respostas. Nesse sentido, o cálculo da frequência foi baseado no total das respostas e não no número de participantes. A maioria dos alunos (70 [ $\mathrm{n}=87]$ ) declarou utilizar estratégias cognitivas. Dentre elas, a de elaboração foi citada em maior número $(43,16 \%[\mathrm{n}=37])$. Foi interessante notar, entretanto, que ninguém declarou utilizar a estratégia de organização.

No que concerne às estratégias metacognitivas, com total geral de 30\% ( $\mathrm{n}=37)$, as de regulação foram as mais citadas $(28,22 \%$ [n=10]). As de planejamento e monitoramento foram mencionadas somente uma vez cada. Dentre elas, a busca de informações com colegas e professores foi a mais citada $(19,36 \%[n=7])$.

A pergunta 5 foi: "Você já ouviu falar em estratégias de aprendizagem? Sim ou não?”; responderam que $\operatorname{sim} 75,8 \% \quad(n=47)$ dos estudantes, e 24,2\% (n=15), que não. Complementando essa questão, a pergunta número 6 foi: "Em sua opinião, o que são estratégias de aprendizagem?”. Para analisar as respostas, foi utilizado um Sistema de Categorização das Respostas existente na literatura (Santos \& Boruchovitch, 2011), no qual 


\section{pro-posıções}

ISSN 1980-6248

foram identificadas as três categorias, para as respostas à questão 6. As respostas à pergunta número 6 estão apresentadas na Tabela 5.

Tabela 5 - Questão 6: Em sua opinião, o que são estratégias de aprendizagem?

\begin{tabular}{lcc}
\hline \multicolumn{1}{c}{ Categorias de respostas } & N & \% \\
\hline Aproxima da definição correta & 37 & 64,92 \\
Confunde estratégias de aprendizagem com estratégias de ensino & 15 & 26,31 \\
Não sabe / em branco / distorcida & 5 & 8,77 \\
Total & 57 & 100 \\
\hline
\end{tabular}

Como se pode observar, $64,92 \%(n=37)$ das respostas se aproximaram de algum tipo de estratégia de aprendizagem. Contudo, 26,31\% $(\mathrm{n}=15)$ corresponderam a estratégias de ensino. Somando as respostas das categorias que não correspondem a estratégias de aprendizagem propriamente ditas, há 35,08\% das respostas $(n=20)$.

\section{Discussão}

Arrolar os conhecimentos de futuros professores a respeito de suas estratégias de aprendizagem constituiu-se no principal objetivo deste estudo, visto que se pôde perceber, por meio da literatura, a relevância temática e também a escassez de pesquisas nacionais sobre o assunto. Para alcançar esse objetivo, optou-se por utilizar um instrumento de natureza qualitativa que pudesse fornecer informações adicionais aos dados levantados tradicionalmente, no Brasil, com o emprego de escalas do tipo likert (Boruchovitch \& Ganda, 2013; Marini \& Boruchovitch, 2014). Assim, os participantes responderam a seis questões abertas e fechadas.

Os estudantes afirmaram, em linhas gerais, refletir sobre sua aprendizagem. Essa reflexão leva-os a uma melhor compreensão, com a tomada de consciência do que fazem e para que fazem, e pode conduzir a mudanças no sentido do(s) objetivo(s) definidos, funcionando como um feedback interno, que lhe permite autorregular a sua aprendizagem (Middleton et al., 2011; Veiga Simão, 2004). Aventa-se que o número elevado de abstenções para a justificativa a essa resposta tenha como possíveis explicações: a dificuldade para refletir sobre o assunto, a falta de capacidade para a expressão de sentimentos, a preguiça de escrever 


\section{pro.posições}

e a pressa para terminar de preencher o questionário. Hipóteses essas que merecem ser alvo de futuras investigações, nas quais entrevistas individuais possam ser utilizadas.

As categorias de resposta para a segunda pergunta, referente à utilidade de pensar sobre o próprio processo de aprendizagem, analisadas em conjunto, permitem inferir que os estudantes parecem se preocupar em processar a informação de modo mais profundo. Esses dados vão ao encontro do que ponderam Boruchovitch e Ganda (2013), Frison e Moraes (2010), Marini e Boruchovitch (2014) e Monereo e Clariana (1993), visto que há presença de competências reguladoras que seriam úteis para bons profissionais. Foi interessante notar que houve alunos que responderam com foco no futuro exercício da profissão. Isso demonstra que seu processo de aprendizagem pode estar mais dirigido à profissão e não só ao atual estágio como aluno. Por um lado, esse dado merece ser mais bem explorado pelas pesquisas futuras, já que um equilíbrio de preocupações no que concerne a ser estudante e ser profissional é bastante desejável durante os cursos de formação; por outro, o fato de os participantes terem respondido que consideravam útil pensar sobre o próprio processo de aprendizagem para sua futura atuação profissional é muito positivo e parece revelar sua consciência quanto à necessidade de possuir um controle metacognitivo sobre o que e como deve ser ensinado. Reconhecimento esse necessário para que ocorra a transferência desse controle para os estudantes, conforme relatado em alguns estudos (Middleton et al., 2011; Monereo \& Clariana, 1993; Perry et al., 2006).

Cabe mencionar ainda alguns resultados que chamaram a atenção, como o percentual de $70 \%$ de uso de estratégias cognitivas e a não utilização, por nenhum participante, das estratégias de organização. Pode-se inferir que elas, por serem mais elaboradas, sejam menos empregadas, pois se referem à identificação das relações subordinadas e superordenadas do material a ser estudado. Ao contrário, as mais utilizadas, de elaboração, são mais comumente disseminadas no contexto escolar, por fazer uso de recursos mnemônicos, entre outras possibilidades.

Já o uso das estratégias metacognitivas correspondeu somente a 30\% do total, sendo a mais citada a busca de informações com colegas e professores, que se caracteriza por ser tanto uma estratégia metacognitiva, porque requer consciência da necessidade de ajuda, quanto de aprendizagem autorregulada, na medida em que os estudantes exibem autodeterminação para superar uma dificuldade, ao pedir ajuda a alguém que tenha mais conhecimento (Newman, 


\section{pro.posıções}

2008; Serafim \& Boruchovitch, 2010). A baixa incidência de menção a estratégias metacognitivas e a ausência de relato de estratégias cognitivas de organização por parte dessa amostra diferem dos dados obtidos por Santos e Boruchovitch (2011), que utilizaram os mesmos instrumentos e objetivos, e se constituem em aspectos importantes que devem ser mais bem desvelados por novas investigações.

Ao lado disso, foi surpreendente o fato de $24,2 \%$ dos alunos terem declarado nunca terem ouvido falar em estratégias de aprendizagem, aliado aos 26,31\% de respostas equivocadas correspondentes a estratégias de ensino. Esses dados não só documentam que ainda há falta de informação quanto a temas importantes, num índice considerável, na amostra, mas também salientam a necessidade de melhoria na formação de futuros docentes.

Foi elevado também o percentual de respostas que não corresponderam a estratégias de aprendizagem (35,08\%). Nessa mesma direção, a concepção de aprender a aprender se apresentou equivocada, como no estudo de Santos e Boruchovitch (2011). Isso se deve, possivelmente, à carência dos conteúdos programáticos sobre estratégias de aprendizagem e sua autorregulação na formação de professores.

Embora a maioria dos estudantes $(64,92 \%)$ tenha definido estratégias de aprendizagem semelhantes ou próximas da significação adotada neste trabalho, eles ainda necessitam ter mais clareza sobre o que elas representam. De modo semelhante aos resultados obtidos no estudo de Santos e Boruchovitch (2011), houve, no presente estudo, uma porcentagem alta de alunos que confundiram estratégias de aprendizagem com estratégias de ensino e que não tinham ideia do que elas eram. Os dados do presente estudo reforçam a necessidade de que sejam oferecidos espaços, nos cursos de formação de professores, para a instrução acerca do uso de estratégias de aprendizagem, tal como reconhecida na literatura (Boruchovitch, Costa, \& Neves, 2005; Knight et al., 2006; McVarish \& Salvatore, 2005; Perry et al., 2006; Romanowski \& Rosenau, 2006).

\section{Considerações finais}

Em linhas gerais, pode-se dizer que o presente estudo oportunizou reflexões que apontam a necessidade de que sejam feitas mais pesquisas com o mesmo intuito desta. Elas poderiam variar procedimentos metodológicos de coleta de dados, de forma a ultrapassar as 


\section{pro.posições}

limitações do presente estudo, que, ao empregar um questionário aplicado coletivamente, embora cuidadosamente acompanhado por uma das pesquisadoras, pode ter propiciado que um considerável número de alunos não tenha respondido algumas das questões, como deveriam, em virtude de precisar escrever. Além disso, deve haver investimento na construção e na validação de instrumentos que possam ser utilizados em conjunto com os de autorrelato, para a observação mais objetiva do comportamento dos respondentes.

Recomenda-se, pois, que a pesquisa futura recorra a aplicações individuais dos mesmos instrumentos, por meio de entrevistas, de modo a obter dados mais aprofundados dos participantes, dando-lhes oportunidade de justificar suas respostas e posições. É igualmente importante que a amostra seja maior e proveniente de vários tipos de instituições. Ademais, como os estudos sobre as estratégias de aprendizagem de adultos, no Brasil, têm se baseado em medidas quantitativas como escalas do tipo likert, seria interessante, ainda, que esforços sejam direcionados à comparação dos dados obtidos por formas diferentes de mensuração. Foi no sentido de contribuir com outro tipo de abordagem, diferente das medidas frequentemente empregadas na literatura, que se optou neste trabalho por um instrumento de natureza qualitativa que não só mapeasse as estratégias de aprendizagem reportadas pelos participantes, mas também que pudesse desvelar aspectos ímpares referentes aos seus processos autorreflexivos no que tange à própria aprendizagem, tão relevantes à formação do futuro professor.

Por fim, espera-se que esta pesquisa possa estimular os cursos de formação docente a capacitar os professores para ativar, nos alunos, a consciência de seus processos cognitivos e metacognitivos. Assim sendo, para que haja mudança de paradigmas nas práticas de professores e alunos, no sentido de agirem de forma crítica e autônoma, é necessário que sejam oferecidos espaços nos cursos de formação de professores para instruí-los sobre o uso de estratégias de aprendizagem, conforme foi apontado nas pesquisas levantadas neste trabalho. 


\section{pro.posıções}

\section{Referências Bibliográficas}

Bardin, L. (2009). Análise de conteúdo. Lisboa: Edições 70.

Bembenutty, H. (2011). Self-regulation of learning in postsecondary education. New directions for teaching and learning, 126, 3-8.

Bortoletto, D., \& Boruchovitch, E. (2013). Learning strategies and emotional regulation of pedagogy students. Paidéia (online), 23(55), 235-242. Retirado em 06 de agosto de 2015, de <http://www.scielo.br/scielo.php?script=sci_arttext\&pid=S0103863X2013000200235\&lng=en\&nrm $=$ iso $>$.

Boruchovitch, E. (1999). Estratégias de aprendizagem e o desempenho escolar: considerações para a prática escolar. Psicologia Reflexão e Crítica, 12(2), 361-367.

Boruchovitch, E. (2009). Escala de estratégias autoprejudiciais (Manuscrito não publicado). Campinas, São Paulo, Brasil: Faculdade de Educação, Universidade Estadual de Campinas.

Boruchovitch, E., Costa, E. R., \& Neves, E. R. C. (2005). Estratégias de aprendizagem: contribuições para a formação de professores nos cursos superiores. In M. C. R. A. Joly, A. A. A. Santos, \& F. F. Sisto (Orgs.), Questões do cotidiano universitário (pp. 238255). São Paulo: Casa do Psicólogo.

Boruchovitch, E., \& Ganda, D. R. (2013). Fostering self-regulated skills in an educational psychology course for Brazilian preservice teachers. Journal of Cognitive Education and Psychology, 12(2), 157-177.

Boruchovitch, E., \& Santos, A. A. A. (2006). Avaliação de estratégias de aprendizagem. In F. F. Sisto, A. A. A. Santos, \& A. P. P. Noronha. (Orgs.), Facetas do fazerer em avaliação psicológica (pp. 107-123). São Paulo: Vetor.

Brophy, J. E., \& Good, T. L. (1986). Teacher behavior and student achievement. In M. C. Wittrock (Org.), Handbook of research on teaching (3a ed., pp. 328-375). New York: Macmillan.

Cázares, D. C., \& Rico, D. G. (2009). Las habilidades metacognitivas en los estudiantes de la Universidad Pedagógica de Durango. Psicogente, 12(21), 29-37. 


\section{pro.posıções}

Dansereau, D. (1978). The development of a learning strategies curriculum. In H. F. O’Neil Jr. (Ed.), Learning strategies (pp. 1-29). New York: Academic Press.

Dembo, M. H. (1994). Applying educational psychology (5a ed.). New York: Longman.

Donche, V., \& Van Petegem, P. (2009). The development of learning patterns of student teachers: A cross-sectional a longitudinal study. Higher Education, 5(2), 35-50.

Dunlosky, J. (1998). Linking metacognitive theory to education. In D. J. Hacker, J. Dunlosky, \& A. C. Graesser (Orgs.), Metacognition in educational theory and practice (pp. 367-382). New Jersey: Lawrence Erlbaum Associates, Inc.

Frison, L. M. B., \& Moraes, M. A. C. (2010). As práticas de monitoria como possibilitadoras dos processos de autorregulação das aprendizagens discentes. Poiésis Pedagógica, 8(2), 144-158.

Gilar, R., Martinez Ruiz, M. Á., \& Costa, J. L. C. (2006). Diary-based strategy assessment and its relationship to performance in a group of trainee teachers. Teaching and Teacher Education: An International Journal of Research and Studies, 23(8), 1334-1344.

Knight, P., Tait, J., \& Yorke, M. (2006). The professional learning of teachers in higher education. Studies in Higher Education, 31(3), 319-339.

Marini, J. A. S., \& Boruchovitch, E. (2014). Estratégias de aprendizagem de alunos brasileiros do ensino superior: considerações sobre adaptação, sucesso acadêmico e aprendizagem autorregulada. Revista E-PSI, 4(1), 102-126.

Mcvarish, J., \& Salvatore, J. (2005). Unlocking awareness and ownership of learning. Academic Exchange Quarterly, 9(4), 177-182.

Middleton, M., Abrams, E., \& Seaman, J. (2011). Resistance and disidentification in reflective practice with preservice teaching interns. New Directions for Teaching and Learning, 126, 67-75.

Monereo, C. F., \& Clariana, M. (1993). Profesores y alumnos estratégicos. Cuando aprender es consecuencia de pensar. Madrid: Pascal.

Newman, R. S. (2008). The motivational role of adaptive help seeking in self-regulated learning. In D. H. Schunk, \& B. J. Zimmerman (Orgs.), Motivation and self-regulated 


\section{pro.posıções}

ISSN 1980-6248

learning: (re) theory, research and applications (pp. 315-337). New Jersey: Lawrence Erlbaum Associates.

Nisbet, J., \& Shucksmith, J. (1986). Learning strategies. London: Routledge \& Kegan Paul.

Noriega, G. T. (2008). Estrategias metacognitivas, motivación académica y rendimiento académico en alumnos ingresantes a una universidad de Lima metropolitana. Persona, 11, 177-193.

Perry, N. E., Phillips, L., \& Hutchinson, L. (2006). Mentoring student teachers to support selfregulated learning. Elementary School Journal, 106(3), 237-254.

Pinto, A. C. (1998). Aprender a aprender o quê? Conteúdos e estratégias. Psicologia, Educaşão e Cultura, 2(1), 37-53.

Quezada, M. T. M. (2005). Estrategias de aprendizaje en estudiantes universitarias. Revista Electrónica Psicologia Científica, 7(13). Retirado em 22 de dezembro de 2014, de http://www.psicologiacientifica.com/estudiantes-universitarias-estrategias-deaprendizaje.

Randi, J. (2004). Teachers as self-regulated learners. Teachers College Record, 106(9), 1825-1853.

Romanowski, J. P., \& Rosenau, L. S. (2006). A contribuição dos processos metacognitivos na formação do pedagogo. Intersaberes, 1(1), 8-27.

Santos, O. J. X., \& Boruchovitch, E. (2011). Estratégias de aprendizagem e aprender a aprender: concepções e conhecimento de professores. Psicologia Ciência e Profissão, 31(2), 284-295.

Serafim, T. M., \& Boruchovitch, E. (2010). A estratégia de pedir ajuda em alunos do ensino fundamental. Psicologia: Ciência e Profissão, 30(2), 381-389.

Silva, A. L., \& Sá, I. (2007). Saber estudar e estudar para saber. Porto, Portugal: Porto Editora.

Somuncuoglu, Y., \& Yildirim, A. (1999). Relationship between achievement goal orientation and use of learning strategies. The Journal of Educational Research, 92(5), 267-277.

Torrano, F. M., \& González-Torres, M. C. (2004). El aprendizaje autorregulado: presente y futuro de la investigación. Revista Electrónica de Investigación Psicoeducativa, 2(1), 203-206. 


\section{pro.posições}

Ugartetxea, J. (2001). Motivación y metacognición, más que una relación. Revista Electrónica de Investigación y Evaluación Educativa, 7(2). Retirado em 22 de dezembro de 2014, de http://www.uv.es/RELIEVE/v7n2/RELIEVEv7n21.htm.

Veiga Simão, A. M. (2004). Integrar os princípios da aprendizagem estratégica no processo formativo dos professores. In A. Lopes da Silva et al., Aprendizagem autorregulada pelo estudante - perspectivas psicológicas e educacionais (pp. 475-484). Porto, Portugal: Porto Editora.

Weinstein, C. E., Acee, T. W., \& Jung, J. H. (2011). Self-regulation and learning strategies. New directions for teaching and learning, 126, 45-53.

Submetido à avaliação em 20 de janeiro de 2015; aprovado para publicação em 18 de outubro de 2015. 


\section{pro.posıções}

\section{Apêndice}

\section{Resposta 1 - Categorias, definições e exemplos}

1 - "Reflexão sobre a melhor maneira de aprender" - esta categoria incluiu as respostas nas quais o participante relatou haver monitoração da compreensão. Um exemplo de resposta para a categoria é: "Para refletir sobre o que se aprende, nas facilidades e nas dificuldades".

2 - "Não ofereceram justificativa" - esta categoria incluiu respostas nas quais não houve argumentos para explicar o que foi indagado.

3 - "Qualidade da atuação profissional" - nesta categoria foram reunidas as respostas que apontaram a dificuldade de o participante se perceber como estudante. Um exemplo de resposta é: "Para ser um bom professor".

4 - "Utilidade da aprendizagem" - esta categoria reuniu as respostas que indicam que os futuros professores apresentam atenção seletiva para o que precisam realmente aprender. Um exemplo de resposta é: "Se acho útil, presto atenção".

5 - "Dependência da explicação do professor" - nesta categoria foram reunidas respostas que indicam a importância dada pelo respondente à maneira como o docente trabalha o conteúdo. Um exemplo de resposta é: "Se o professor despertar meu interesse eu fico achando que aquilo vai ser importante".

\section{Resposta 2 - Categorias, definições e exemplos}

1 - "Significação da aprendizagem” - esta categoria incluiu respostas que relacionam a reflexão sobre a aprendizagem à preocupação em dotar de sentido o que é aprendido. Um exemplo de resposta é: "Para encontrar a melhor maneira de tornar a aprendizagem com mais valor".

2 - "Identificação da melhor forma de aprender" - nesta categoria estão incluídas respostas que associam a autorreflexão à importância de monitoramento e regulação do que é aprendido por parte do estudante. Uma das respostas foi: "Para fazer autoavaliação e saber o que precisa mudar". 


\section{pro.posıções}

3 - "Importância para a atuação profissional" - esta categoria contém respostas que evidenciam os benefícios da autorreflexão para a futura carreira. Um exemplo de resposta é: "Vai ser útil depois na carreira também".

4 - "Não oferecerem justificativa" - esta categoria incluiu respostas nas quais os participantes reconhecem a importância da autorreflexão sobre a aprendizagem, sem, contudo, oferecer uma justificativa.

\section{Resposta 3 - Categorias, definições e exemplos}

1 - "Qualidade da atuação profissional" - nesta categoria foram reunidas as respostas que evidenciaram o reconhecimento da utilidade da autorreflexão por parte do participante para as suas atividades docentes futuras. Um exemplo de resposta para a essa categoria é: "Para ter mais segurança para dar aulas".

2 - "Avaliação dos alunos" - esta categoria agrupou respostas de estudantes que creem que precisam entender o próprio processo de aprendizagem para poder avaliar o dos futuros alunos. Um exemplo de resposta é: “Tem que saber como cobrar dos alunos”.

3 - "Não ofereceram justificativa" - para esta categoria não houve argumentos para explicar as respostas.

\section{Resposta 6 - Categorias, definições e exemplos}

1 - Aproxima da definição correta: esta categoria incluiu respostas nas quais o participante relata uma definição de estratégias de aprendizagem semelhante à significação dada por Nisbett e Shucksmith (1986) e Dansereau (1978) ou próxima dela. Um exemplo de resposta para esta categoria é: "Ideias e ações que facilitam o processo de aprendizagem".

2 - Confunde estratégias de aprendizagem com estratégias de ensino. Um exemplo é: "Métodos de ensino para que o aluno se aproprie do conhecimento".

3 - Não sabe/ em branco/ distorcida. Um exemplo de resposta é: "Não sei e fiquei curiosa

$$
\text { para }
$$

saber

o

que

é”. 
